\title{
Low incidence of daily active tobacco smoking in patients with symptomatic COVID-19 infection
}

Makoto Miyara ${ }^{1}$, Florence Tubach ${ }^{1}$, Zahir Amoura ${ }^{1}$

1 Assistance Publique - Hôpitaux de Paris

\section{Abstract}

Importance: As the pandemic of COVID-19 is still under progression, identification of prognostic factors is a global challenge. Among epidemiological risk factors, the role of smoking, to date, is unclear.

Objective: To accurately evaluate a possible correlation of daily smoking with an increased susceptibility to SARS-CoV-2 infection.

Participants: We estimated the rates of daily current smokers in COVID-19-infected patients in a large French university hospital between February 28th 2020 and March 30th 2020 for outpatients and from March 23rd till April 9th 2020 for inpatients.

Design: The rates from both groups were compared to those of daily current smokers in the 2018 French general population, established in 2018, after standardization of the data for sex and age.

Results: The inpatient group was composed of 343 patients, median age 65 yr: 206 men (60.1\%, median age $66 \mathrm{yr}$ ) and 137 women (39.9\%, median age $65 \mathrm{yr}$ ) with a rate of daily smokers of $4.4 \%$ (5.4\% of men and $2.9 \%$ of women).The outpatient group was composed of 139 patients, median age 44 yr: 62 men (44.6 \%, median age 43 yr, and 77 women (55.4 \%, median age 44). The daily smokers rate was 5.3\% (5.1\% of men and $5.5 \%$ of women). In the French population, the daily smokers rate is $25.4 \%$ (28.2\% of men and $22.9 \%$ of women).

The rate of current daily smokers was significantly lower in COVID-19 outpatients and inpatients (80.3\% and $75.4 \%$, respectively), as compared to that in the French general population with standardized incidence ratios according to sex and age of 0.197 [0.094 - 0.41] and 0.246 [0.148 - 0.408]. These ratios did not significantly differ between the two groups $(\mathrm{P}=0.63)$.

Conclusions and relevance: Our study highlights for the first time a dramatic decreased prevalence of daily current smokers both in COVID-19 outpatients and inpatients as compared to the general population. 


\section{Introduction}

As the pandemic of COVID-19, caused by the severe acute respiratory syndrome coronavirus 2 (SARS-CoV-2), is still under progression, the identification of prognostic factors is a global challenge. Among epidemiological risk factors, the role of smoking, to date, is unclear. Smoking has been initially found associated with adverse disease prognosis of COVID-19[1], although this finding remains controversial[2]. Reported rates of current smokers among SARS-CoV-2-infected patients are heterogeneous, rang ing from 1.4\% to 12.5\% (T ABLE 1 [1, 3-10]). The rates of current smokers remain however striking ly low for the middle-aged Chinese population (median age: 47.0 years; range: 35.0-58.0; in Guan et al.[1]). These data notwithstanding, no firm conclusions can be drawn from the available COVID-19 studies because main potential confounders, like age and sex, were not taken into account. Additionally, these studies included mostly hospitalized patients, and the low rate of current smokers may be related to high rate of patients with comorbidities (smokers having been advised to quit) and thus to COVID-19 severity. This could therefore introduce a confusion bias. To allow for a valid comparison with the general population, smoking rates used as a reference should have been evaluated at a time as close as possible to time of COVID pandemic and the same definitions of current smokers should be used for both the COVID-19 population and the general population, which was not clear in the previous studies. The last available study of the Chinese general population in 2015 reported rates of current smokers of 52\% for men and $2.5 \%$ for women[11]. Very recently, the US Center of Disease Control reported an analysis of current smoker rate among US COVID-19 patients which was found to be $1.3 \%$ for the whole population of COVID-19 patients, $1 \%$ for outpatients, $2 \%$ for patients, not hospitalized in an ICU, and 1\% in ICU-admitted patients[12]. However, the level of missing smoking status was very high and no comparison with the general population was performed.

Therefore, the hypothetic « protective » effect of current smoking on the risk of SARSCoV-2 infection that can be extrapolated from the low current smoker rate has yet to be determined. To accurately evaluate whether or not current smoking is associated with the risk of contracting a symptomatic SARS-CoV-2 infection, we have compared the rates of current smokers of two groups, one composed of both COVID-19 outpatients (not subsequently hospitalized) and one of COVID-19 inpatients with those in the 2018 French general population after standardization by sex and age.[13] 


\begin{tabular}{|c|c|c|c|c|c|c|c|}
\hline & Median & $\operatorname{Sex}(\%)$ & & & Current & & \\
\hline $\begin{array}{l}\mathrm{N} \text { (total } \\
\text { number } \\
\text { of } \\
\text { patients) }\end{array}$ & $\begin{array}{l}\text { Age } \\
\text { (yr) }\end{array}$ & Male/female & Country & $\begin{array}{l}\% \text { of } \\
\text { current } \\
\text { smokers }\end{array}$ & $\begin{array}{l}\text { Smoking rate } \\
\text { (\%) in the } \\
\text { general } \\
\text { population } \\
\text { Male/Female } \\
\text { (date) }\end{array}$ & $\begin{array}{l}\text { Possible } \\
\text { confounders of } \\
\text { smoking status } \\
\text { analysis }\end{array}$ & Ref \\
\hline 1099 & 47 & $58.1 / 41.9$ & China & 12.6 & $\begin{array}{l}52 \% / 2.5 \% \\
(2015)\end{array}$ & $\begin{array}{l}\text { Outpatients } \\
\text { and Inpatients } \\
\text { mixed }\end{array}$ & 1 \\
\hline 191 & 56.0 & $62 / 38$ & China & 6.0 & “ & $\begin{array}{l}\text { No age, and } \\
\text { sex-matched } \\
\text { control } \\
\text { population }\end{array}$ & 10 \\
\hline 41 & 49 & $73 / 27$ & China & 7.0 & “ & $\begin{array}{l}\text { No age, and } \\
\text { sex-matched } \\
\text { control }\end{array}$ & 3 \\
\hline
\end{tabular}

Table 1 Prevalence of smokers in COVID-19 patients in published series

\section{Material and methods}

\section{Patients and design}

This is a cross-sectional survey investigating the rate of current smokers in patients with a diagnosis of COVID-19, both in hospitalized patients (representing the severe symptomatic cases of COVID-19) and in outpatients (i.e. patients who represent the nonsevere symptomatic cases of this infection). Current smoker rates were compared to those of the French population as a reference, after standardization by age and sex. Elig ible patients were those with a confirmed diagnosis of COVID-19 at the APHP Pitié- 
Salpêtrière Hospital, Paris, France, either hospitalized in medical wards of medicine, but not in ICUs (inpatients) or having consulted for this infection in the infectious disease department and who did not require hospital care until end of the acute infectious episode (outpatients). The period of inclusion ran from the 23rd of March to 9th of April 2020 for inpatients and from the 28th of February to the 30th of March 2020 for outpatients.

This study is observational. All data were collected in the context of care and were collected in completely anonymous sheets and therefore, in accordance with the French law, including the GPRD, informed consent of the patient was not sought. The study has been approved by the ethics committee of the Sorbonne University (2020 - CER-202013)

\section{Definitions and data collected}

Confirmed COVID-19 was defined as a positive result on real-time reverse-transcriptasepolymerase-chain-reaction (RT-PCR) assay of nasal and pharyngeal swab specimens. Smoking status was collected and patients were specifically asked whether they were current smokers (and if so, to provide details on their smoking habits: daily or occasional smoking, type of tobacco products used, number of daily cigarettes), former smokers, or not smokers ever).

Daily smokers are individuals reporting daily smoking or reporting a daily frequency of the number of cigarettes (manufactured or rolled) or other tobacco products (cigars, cigarillos, pipe, shisha)[13]. Occasional smokers are individuals reporting infrequent, but not daily smoking. The group of ex-smokers includes anyone having smoked in the past, occasionally or daily, and had abstained from smoking prior to the time of investigation. The term "never smoker" designated people who had never smoked. The quantities of tobacco smoked were calculated using the following equivalences: 1 cigar $=1$ cigarillo $=2$ cigarettes.

In addition to smoking status, the following data were extracted from the medical charts: age, sex, comorbidities, known to have potentially an impact on the prognosis of COVID19, including diabetes, hypertension, obesity, immunodepression and respiratory disease (such as COPD, other clinical manifestations of COVID-19 and out- or inpatient status.

\section{Smoking rate in the population of reference}

The French general population was used as a reference to compute the SIR. Recent rates of current daily smokers have been reported for the year 2018 by sex and age class (of 10 years) from the General Survey "Baromètre de Santé Publique France" of the French population, cross sectional phone survey made yearly on a representative sample of 18- 
75 year-old people living in mainland France, with a on 2-level random sampling [13]. The 2018 survey involved a sample of 9,074 individuals. The completion of the survey took place from January 10 to July 25, 2018 and used the same definitions of daily smokers, occasional smokers, former smokers and never smokers as described above.

\section{Statistical analysis}

A descriptive analysis has been made by group (inpatients - outpatients). Qualitative variables were described by numbers and percentages, and quantitative variables by median and interquartile range. Inpatients and outpatients were compared for qualitative variables with Pearson Chi2 tests or Fisher's exact test as appropriate and for quantitative variables with Wilcoxon sum rank test.

The SIRs were used to compare current daily smoker rates in the COVID-19 inpatients and outpatients, respectively, with those of current daily smokers in a reference population, here the French general population in 2018. The estimated SIR and its 95\% confidence interval is the ratio between the observed number of current daily smokers among the COVID-19 patients and the number of current daily smokers that would be expected, on the basis of age- and gender-specific current daily smokers rates in the general population. The main analysis involved all included patients, and those older than 75 years were considered in the 65-75 years age class for standardization, which for our hypothesis is conservative approach, because current smoker rates decreases with age. For 7 outpatients and 2 inpatients, medical charts, and thus smoking status, was not available. We did not include the latter patients in the main analysis for reasons that the lack of medical history was very likely to be at random regarding smoking status. We performed two sensitivity analysis, one excluding patients older than 75 years, the other considering these nine patients with missing data on the smoking status as current smokers.

\section{Results \\ Demographic and Clinical Characteristics}

A total of 343 inpatients and 139 outpatients were included. The demographic and clinical characteristics of the two groups are shown in TABLE 2.

The inpatient group was composed of 343 patients, median age 65 yr: 206 men (60.1\%, median age $66 \mathrm{yr}$ ) and 137 women (39.9\%, median age $65 \mathrm{yr}$ ). The rate of daily smokers was 4.4 (5.4\% of men and $2.9 \%$ of women).

The outpatient group was composed of 139 patients, median age 44 yr: 62 men (44.6\%, 
median age $43 \mathrm{yr}$, and 77 women (55.4\%, median age 44$)$. The daily smokers rate was $5.3 \%$ ( $5.1 \%$ of men and $5.5 \%$ of women).

As described by others[1], hypertension (41.4\%), diabetes (27.7\%), obesity (14.4\%) and immune deficiencies (17.8\%) are frequently observed in inpatients while COPD is less frequent (7.9\%). Those comorbidities were significantly less frequent in outpatients with hypertension counting for 12.1\%, $(P<0.0001)$, diabetes for 5.3\% ( $P<0.0001)$, obesity for 7.6\% ( $P=0.045)$, immunodeficiencies for $3.0 \%(P<0.0001)$, and COPD for $1.5 \%(P=0.009)$. As shown in figure 1, age distribution differs between outpatients and inpatients with younger patients in outpatients and older patients in inpatients.

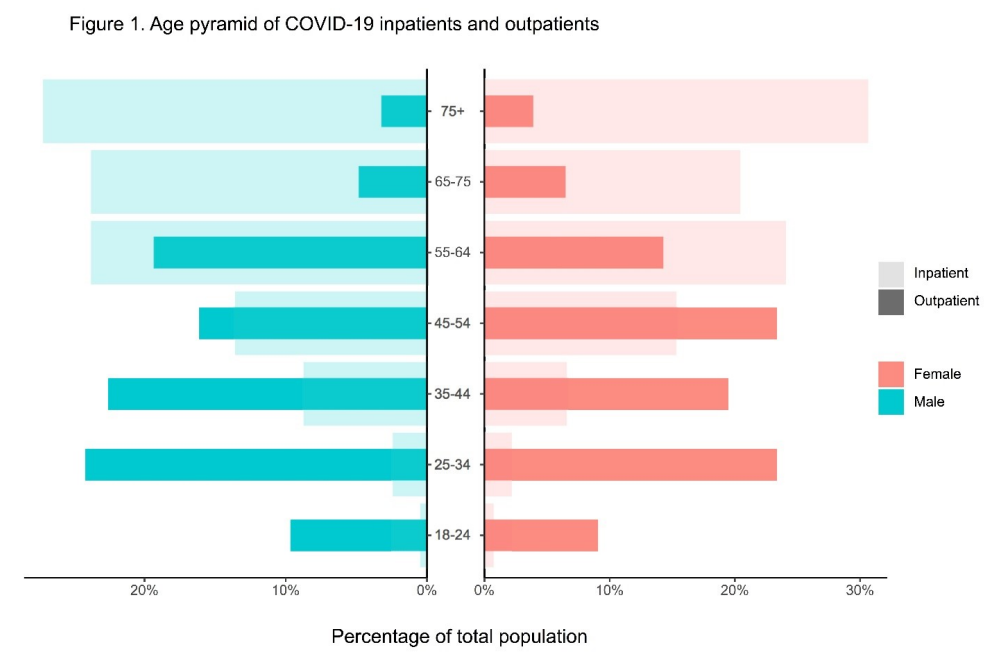

Figure 1 Age pyramid of COVID-19 inpatients and outpatients.

Dark and light shaded histograms represent outpatients and inpatients with confirmed COVD-19 status, respectively

The rates of daily current smokers in inpatients (4.4\%) did not significantly differ from that in outpatients (5.4\%; $P=0.67 ;$ TABLE 2$)$. Occasional smoking was slightly more frequent in outpatients than in inpatients ( 4.6 vs $1.8 \% ; P=0.10$ ) but the number of people concerned was small. 


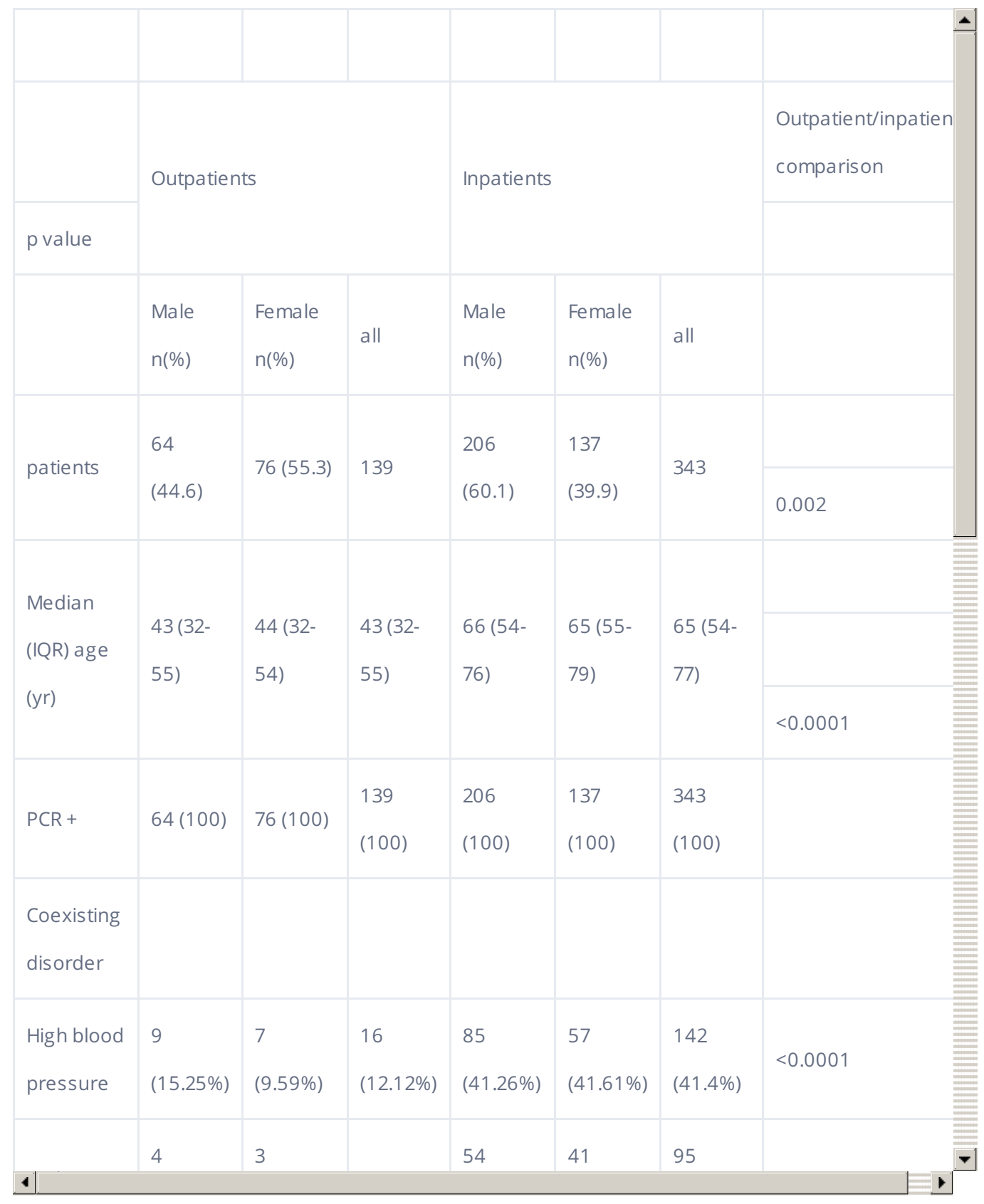

Table 2 Clinical characteristics and smoking habits of COVID-19 patients

\section{Comparison with the French general population}

The Standardized Incidence Ratio (SIR) for daily current smokers according to sex and age is shown in FIGURE 2. SIRs were 0.197 [0.094 - 0.414] and 0.246 [0.148 - 0.408] for outpatients and inpatients, respectively. The SIR in outpatients did not significantly differ from that in inpatients $(p=0.63)$. Sensitivity analyses yielded similar results (supplemental tables). 
Figure 2. Incidence rates and standardized incidence ratio in smoking COVD-19 patients

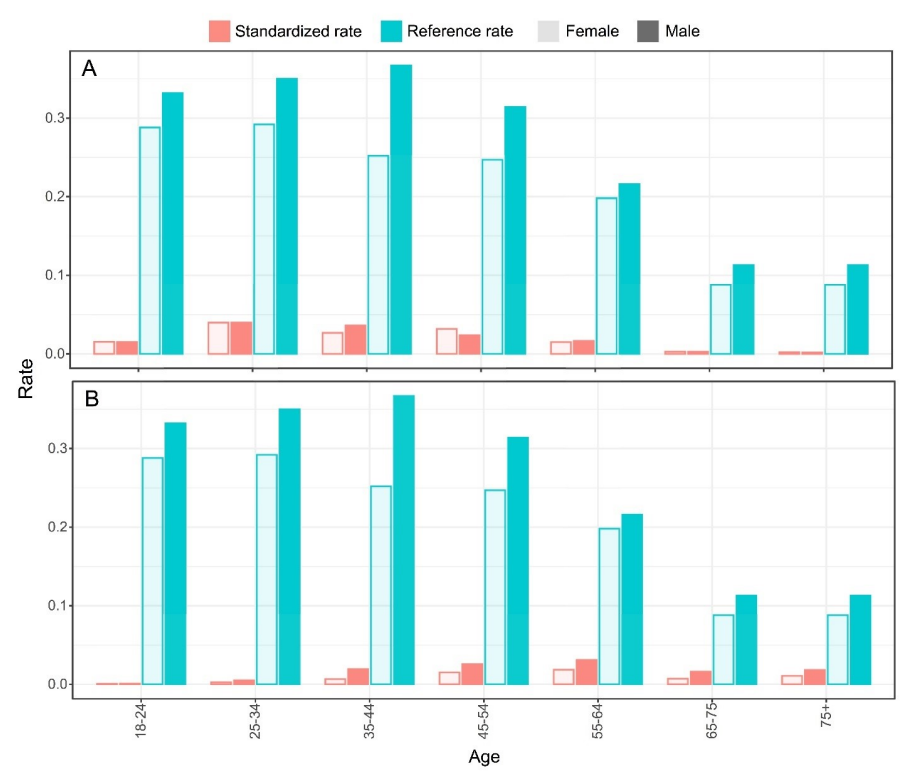

Figure 2. Incidence rates and standardized incidence ratio in smoking COVD-19 patients

The daily cigarette consumption of current smokers is shown in TABLE 3. In 2018, the mean number of daily cigarettes by current smokers in the French general population was 13.0 cigarettes, or equivalent, with 14.0 cigarettes for men and 11.9 for women[13]. Two out of seven outpatients and 5/15 inpatients were heavy daily current smokers with a daily number of 20, or more, cigarettes (data unavailable for 1 inpatient). 


\begin{tabular}{|c|c|c|c|}
\hline & $\operatorname{sex}$ & age & daily cigarette consumption \\
\hline OUT1 & $\mathrm{H}$ & 47 & 5 \\
\hline OUT2 & $\mathrm{F}$ & 37 & 5 \\
\hline OUT3 & $\mathrm{F}$ & 25 & $<5$ \\
\hline OUT4 & M & 27 & 5 \\
\hline OUT5 & $\mathrm{F}$ & 28 & $>=20$ \\
\hline OUT6 & $\mathrm{M}$ & 55 & $>=20$ \\
\hline OUT7 & $\mathrm{F}$ & 18 & 10 \\
\hline IN1 & M & 49 & $<5$ \\
\hline IN2 & $\mathrm{F}$ & 57 & $>=20$ \\
\hline IN3 & M & 48 & NA ( transfer in ICU) \\
\hline IN4 & M & 60 & $>=20$ \\
\hline IN5 & $\mathrm{F}$ & 81 & $>=20$ \\
\hline IN6 & M & 74 & $>=20$ \\
\hline IN7 & $\mathrm{F}$ & 39 & 5 \\
\hline IN8 & $\mathrm{M}$ & 36 & $<5$ \\
\hline
\end{tabular}

Table 3 Daily cigarette consumption of outpatient and inpatient current smokers

\section{Discussion}

Our cross sectional study reports for the first time a decreased prevalence of daily current smokers in both COVID-19 outpatients and inpatients, as compared to the general population. Our findings clearly support the hypothesis that current daily smoking may be a protective factor ag ainst COVID-19 SARS-CoV-2 infection, or at least symptomatic COVID-19 SARS-CoV-2 infection. The SIRs of current daily smoking in COVID-19 outpatients and inpatients were 0.197 [0.094 - 0.41] and 0.246 [0.148 - 0.408], respectively, which points to a significantly decreased current daily smoker rate of $80.3 \%$ and $75.4 \%$ in outpatients and inpatients, respectively, as compared to the French general 
population. The SIRs did not differ between outpatients and inpatients, suggesting that the protective effect of smoking covered the whole population of symptomatic (both non-severe and severe) patients.

Current smoking status seems to confer a protective effect on the risk of contracting symptomatic COVID-19. However, $4.4 \%$ of inpatients and $5.4 \%$ of outpatients were daily current smokers, and among them two outpatients and five inpatients were heavy smokers (i.e. smoked 20 or more cigarettes a day), representing $1.5 \%$ of the cohort of COVID-19 patients in this study.,

Under or over-reporting of smoking status is a major concern of study on smoking habits. Actually, smoking status is more often reported in medical files in case of comorbidities. In our study, we have a very low rate of missing data on smoking status, and sensitivity analyses have shown that they do not alter the robustness of our results.

One pending question was "Does smoking prevent SARS-CoV-2 from infecting a person, or does it affect the severity of the disease?" Our study is the first one to include and analyze separately the smoking pattern of COVID-19 outpatients (non severe cases) and inpatients (severe cases). Indeed, all previous studies, but two, which reported smoking rates included only inpatients (TABLE 1). Unfortunately, smoking data from inpatients and outpatients were mixed in the Guan study[1] and there was a lot of missing data in the report from the $C D C[12]$. It is of note that due to the low number of daily current smokers in our study, we could not conclude whether daily current smoking has an impact on the COVID-19 severity. However, SIR of inpatients did not differ from SIR in outpatient. In addition, the more severe COVID-19 patients, hospitalized in an ICU, were not included in the present study. A larger study including ICU patients will certainly help to conclusively address this question.

Our findings should be cautiously interpreted in light of its limitations. The study was performed in 2020 and the results were compared to the data obtained from the French general population's smoking rate in 2018. However, we are not aware of such a dramatic trend of decrease in tobacco use in France since mid 2018 that could explain our results. The SIRs were estimated with the assumption that the studied population who lives in a limited area around a Parisian hospital has the same smoking habits as the general French population. Actually, smoking rates differ across socio-professional categories, and therefore may differ across geographic areas. It is furthermore of note that in the present study healthcare workers are over-represented in the outpatient group, due to systematic testing at their work place for healthcare workers with symptoms, but not in the inpatient group (data not shown). It is, however, very unlikely 
that the very low SIRs that were estimated both for the out- and inpatient groups are the result of the study setting. Finally, in our study, smoking status was assessed only in symptomatic COVID-19 patients while a large part of infected individuals are asymptomatic[14]

Because this is a cross-sectional study, we cannot confirm the causality of this association. We cannot also identify which of the many compounds of tobacco exerts the protective effect of smoking on COVID-19. There are however, sufficient scientific data to suggest that smoking protection is likely to be mediated by nicotine. The SARSCoV2 is known to use the angiotensin converting enzyme 2 (ACE2) as a receptor for cell entry[15-17], and there is evidence that nicotine modulates ACE2 expression[18] which could in turn modulates the nicotinic acetyl choline receptor (manuscript submitted). Inour hypothesis, the SARS-CoV2 would affect the control of the nicotine receptor by acetylcholine. This hypothesis could also explain why previous studies have found an association between smoking and Covid severity[1, 9, 10]. As hospitals generally impose smoking cessation and nicotine withdrawal at the point of hospitalization, tobacco (nicotine) cessation could release nicotine receptors, that are increased in smokers, and lead to a rebounding effect responsible for the worsening observed in hospitalized smokers.

There could be significant implications of our results in terms of prevention, and for practice in hospitals. Nicotine administration, e.g. via a transcutaneous route might be a promising therapeutic option to recapitulate the protecting effect of smoking over SARS CoV2 infection in non-smokers, either as a prevention strategy, or as a curative strategy. The promotion of smoking to avoid COVID-19 is however not an option, this is obviously unacceptable, given the deleterious benefit/risk ratio of smoking which is responsible for a very heavy public health burden with more than 78000 deaths per year in France.

\section{REFERENCES}

1. Guan WJ, Ni ZY, Hu Y, Liang WH, Ou CQ, He JX, Liu L, Shan H, Lei CL, Hui DSC, Du B, Li LJ, Zeng G, Yuen KY, Chen RC, T ang CL, Wang T, Chen PY, Xiang J, Li SY, Wang JL, Liang ZJ, Peng YX, Wei L, Liu Y, Hu YH, Peng P, Wang JM, Liu JY, Chen Z, Li G, Zheng ZJ, Qiu SQ, Luo J, Ye CJ, Zhu SY, Zhong NS. Clinical Characteristics of Coronavirus Disease 2019 in China. N EnglJ Med 2020.

2. Lippi G, Henry BM. Active smoking is not associated with severity of coronavirus disease 2019 (COVID-19). Eur J Intern Med 2020. 
3. Huang C, Wang Y, Li X, Ren L, Zhao J, Hu Y, Zhang L, Fan G, Xu J, Gu X, Cheng Z, Yu T, Xia J, Wei Y, Wu W, Xie X, Yin W, Li H, Liu M, Xiao Y, Gao H, Guo L, Xie J, Wang G, Jiang R, Gao Z, Jin Q, Wang J, Cao B. Clinical features of patients infected with 2019 novel coronavirus in Wuhan, China. Lancet 2020; 395:497-506.

4. L Liu J, Liu Ouyang PG, Hai sheng Wu, Peng Fu, Yu liang Chen, Dan Yang, Xiao yu Han, Yu kun Cao, Osamah Alwalid, Juan Tao, Shu yi Peng, He shui Shi, Fan Yang, Chuan sheng Zheng. Epidemiological, Clinical Characteristics and Outcome of Medical Staff Infected with COVID-19 in Wuhan, China: A Retrospective Case Series Analysis. medRxiv 2020.

5. Liu W, Tao ZW, Lei W, Ming-Li Y, Kui L, Ling Z, Shuang W, Yan D, Jing L, Liu HG, Ming Y, Yi H. Analysis of factors associated with disease outcomes in hospitalized patients with 2019 novel coronavirus disease. Chin Med J (Engl) 2020.

6. Mo P, Xing Y, Xiao Y, Deng L, Zhao Q, Wang H, Xiong Y, Cheng Z, Gao S, Liang K, Luo M, Chen T, Song S, Ma Z, Chen X, Zheng R, Cao Q, Wang F, Zhang Y. Clinical characteristics of refractory COVID-19 pneumonia in Wuhan, China. Clin Infect Dis 2020. 7. Wan S, Xiang Y, Fang W, Zheng Y, Li B, Hu Y, Lang C, Huang D, Sun Q, Xiong Y, Huang X, Lv J, Luo Y, Shen L, Yang H, Huang G, Yang R. Clinical features and treatment of COVID-19 patients in northeast Chong qing. J Med Virol 2020.

8. Yang X, Yu Y, Xu J, Shu H, Xia J, Liu H, Wu Y, Zhang L, Yu Z, Fang M, Yu T, Wang Y, Pan S, Zou X, Yuan S, Shang Y. Clinical course and outcomes of critically ill patients with SARS-CoV-2 pneumonia in Wuhan, China: a single-centered, retrospective, observational study. Lancet Respir Med 2020.

9. Zhang لإل Dong X, Cao YY, Yuan YD, Yang YB, Yan YQ, Akdis CA, Gao YD. Clinical characteristics of 140 patients infected with SARS-CoV-2 in Wuhan, China. Allergy 2020. 10. Zhou F, Yu T, Du R, Fan G, Liu Y, Liu Z, Xiang J, Wang Y, Song B, Gu X, Guan L, Wei Y, Li H, Wu X, Xu J, Tu S, Zhang Y, Chen H, Cao B. Clinical course and risk factors for mortality of adult inpatients with COVID-19 in Wuhan, China: a retrospective cohort study. Lancet 2020; 395:1054-62.

11. Prevention CCfDCa. China Adult Tobacco Survey Report. Beijing, 2015. 2015.

12. Preliminary Estimates of the Prevalence of Selected Underlying Health Conditions Among Patients with Coronavirus Disease 2019 - United States, February 12-March 28, 2020. MMWR Morb Mortal Wkly Rep 2020; 69:382-6.

13. Andler R, Richard JB, Guignard R, Quatremère G, Verrier F, Gane J, Nguyen-Thanh V. Reduction of daily smoking rate among adults: results from the 2018 santé publique france health barometer. Bull Epidémiol Hebd 2019; 15:271-7.

14. Lauer SA, Grantz KH, Bi Q, Jones FK, Zheng Q, Meredith HR, Azman AS, Reich NG, Lessler J. The Incubation Period of Coronavirus Disease 2019 (COVID-19) From 
Publicly Reported Confirmed Cases: Estimation and Application. Ann Intern Med 2020.

15. Lan J, Ge J, Yu J, Shan S, Zhou H, Fan S, Zhang Q, Shi X, Wang Q, Zhang L, Wang X. Structure of the SARS-CoV-2 spike receptor-binding domain bound to the ACE2 receptor. Nature 2020.

16. Hoffmann M, Kleine-Weber H, Schroeder S, Kruger N, Herrler T, Erichsen S, Schiergens TS, Herrler G, Wu NH, Nitsche A, Muller MA, Drosten C, Pohlmann S. SARSCoV-2 Cell Entry Depends on ACE2 and T MPRSS2 and Is Blocked by a Clinically Proven Protease Inhibitor. Cell 2020.

17. Yan R, Zhang Y, Li Y, Xia L, Guo Y, Zhou Q. Structural basis for the recognition of SARS-CoV-2 by full-leng th human ACE2. Science 2020; 367:1444-8.

18. Oakes JM, Fuchs RM, Gardner JD, Lazartigues E, Yue X. Nicotine and the reninangiotensin system. Am J Physiol Regul Integr Comp Physiol 2018; 315:R895-R906. 


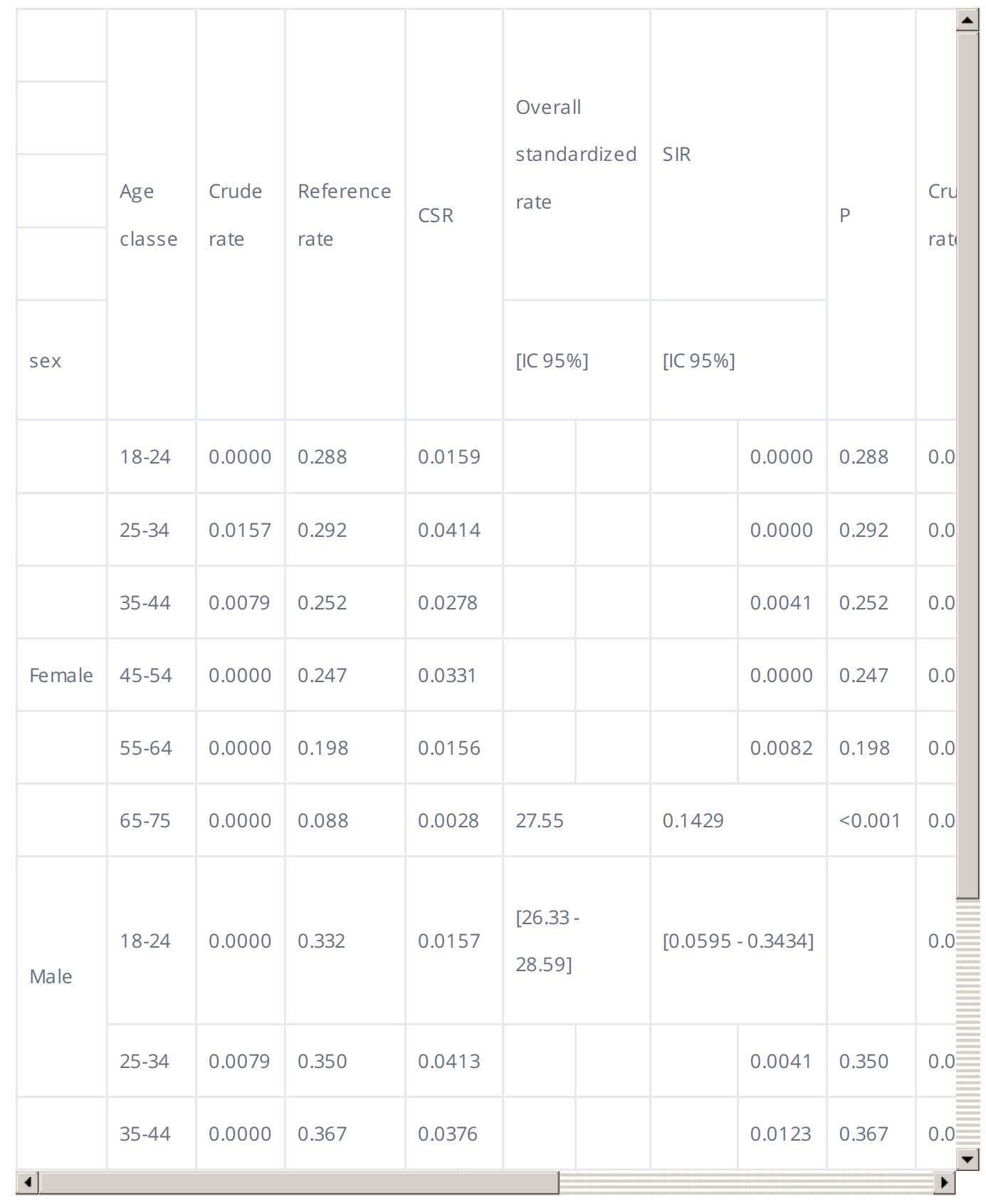

Supplemental Table 1: excluding patients older than 75 years 


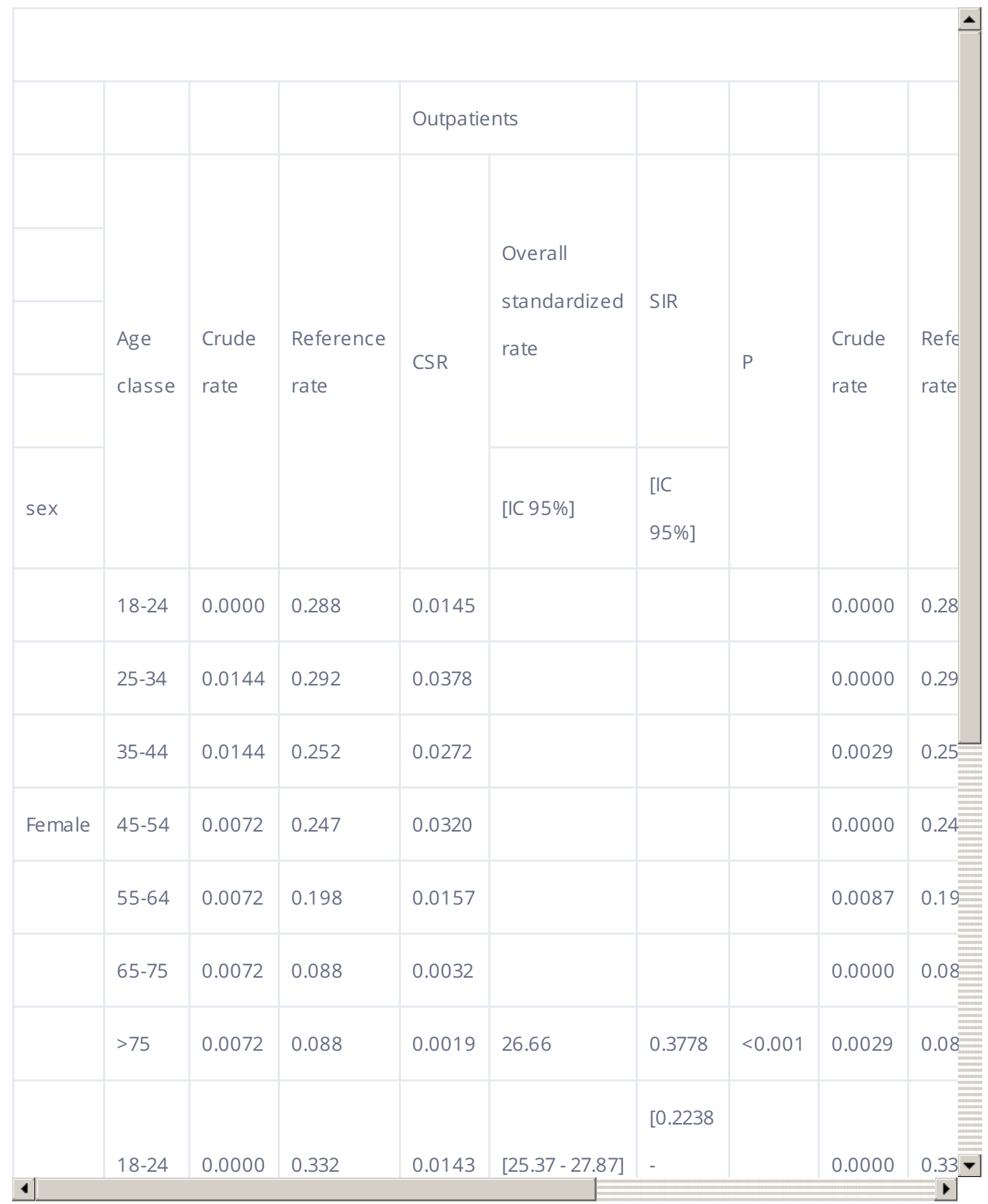

Supplemental Table 2: considering the 9 patients with missing data on the smoking status as current smokers

\section{Authors list:}

Makoto Miyara1*, Florence Tubach2*, Valérie Pourcher3, Capucine Morélot-Panzini4 , Julie

Pernet5, Julien Haroche6, Said Lebbah2, Elise Morawiec7, Guy Gorochov1 , Eric Caumes3,

Pierre Hausfater5, Alain Combes8, Thomas Similowski4 , Zahir Amoura6\#

1 Sorbonne Université, Inserm UMR-S 1135, Centre d'Immunologie et des Maladies Infectieuses (CIMI-Paris), Groupe Hospitalier Universitaire APHP.Sorbonne-université, site Pitié-Salpêtrière, Département d'immunologie, 
2 Sorbonne Université, Inserm UMR-S 1136, Institut Pierre Louis d'Epidémiologie et de Santé Publique, Groupe Hospitalier Universitaire APHP.Sorbonne-Université, site PitiéSalpêtrière, Département de Santé Publique, Unité de Recherche Clinique Pitié, CIC-1422, F75013, Paris, France

3 Sorbonne Université, Inserm UMR-S 1136, , Institut Pierre Louis d'Epidémiologie et de Santé Publique, Groupe Hospitalier Universitaire APHP.Sorbonne-Université, site PitiéSalpêtrière, Service des maladies infectieuses et tropicales 4 Sorbonne Université, Inserm, UMRS-1158 ; APHP, Groupe Hospitalier Universitaire APHP-Sorbonne Université, site Pitié-Salpêtrière, Service de Pneumologie et Réanimation Médicale (Département R3S), Paris, France 5 Sorbonne Université, GRC-14 BIOSFAST, UMR Inserm 1166, IHU ICAN, Service d'accueil des Urgences, Groupe Hospitalier Universitaire APHP.Sorbonne-université, site PitiéSalpêtrière, Paris, France 6 Sorbonne Université, Inserm UMR-S 1135, Centre d'Immunologie et des Maladies Infectieuses (CIMI-Paris), Groupe Hospitalier Universitaire APHP.Sorbonne-université, site Pitié-Salpêtrière, service de médecine interne 2

7 APHP, Groupe Hospitalier Universitaire APHP.Sorbonne Université, site PitiéSalpêtrière, Service de Pneumologie et Réanimation Médicale (Département R3S), Paris, France 8 Sorbonne Université, Inserm, UMRS_1166-ICAN, Institute of Cardiometabolism and Nutrition, APHP. Sorbonne-université, Service de médecine intensive-réanimation, Institut de Cardiologie, site Pitié-Salpêtrière, F-75013 PARIS, France. *Contributed equally \#corresponding author: zahir.amoura@aphp.fr 